\title{
The outcomes of most aggressive interactions among closely related bird species are asymmetric
}

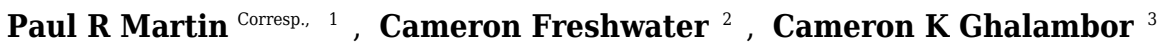 \\ 1 Department of Biology, Queen's University, Kingston, Ontario, Canada \\ 2 Department of Biology, University of Victoria, Victoria, British Columbia, Canada \\ 3 Department of Biology and Graduate Degree Program in Ecology, Colorado State University, Fort Collins, Colorado, United States \\ Corresponding Author: Paul R Martin \\ Email address: pm45@queensu.ca
}

Aggressive interactions among closely related species are common, and can play an important role as a selective pressure shaping species traits and assemblages. The nature of this selective pressure depends on whether the outcomes of aggressive contests are asymmetric between species (i.e., one species is consistently dominant), yet few studies have estimated the prevalence of asymmetric versus symmetric outcomes to aggressive contests. Here we use previously published data involving 26,212 interactions between 270 species pairs of birds from 26 taxonomic families to address the question: How often are aggressive interactions among closely related bird species asymmetric? We define asymmetry using (i) the proportion of contests won by one species, and (ii) statistical tests for asymmetric outcomes of aggressive contests. We calculate these asymmetries using data summed across different sites for each species pair, and compare results to asymmetries calculated using data separated by location. We find that $80 \%$ of species pairs had aggressive outcomes where one species won $80 \%$ or more of aggressive contests. We also find that the majority of aggressive interactions among closely related species show statistically significant asymmetries, and above a sample size of 52 interactions, all outcomes are asymmetric following binomial tests. Species pairs with dominance data from multiple sites showed the same dominance relationship across locations in $93 \%$ of the species pairs. Overall, our results suggest that the outcome of aggressive interactions among closely related species are usually consistent and asymmetric, and should thus favor ecological and evolutionary strategies specific to the position of a species within a dominance hierarchy. 
6 The outcomes of most aggressive interactions among closely related bird species

7 are asymmetric

8

9 Paul R. Martin ${ }^{1}$, Cameron Freshwater ${ }^{2}$, Cameron K. Ghalambor ${ }^{3}$

10

$11{ }^{1}$ Department of Biology, Queen’s University, Kingston, Ontario, Canada

$12{ }^{2}$ Department of Biology, University of Victoria, Victoria, British Columbia, Canada

$13{ }^{3}$ Department of Biology and Graduate Degree Program in Ecology, Colorado State

14 University, Fort Collins, Colorado, USA

15

16 Corresponding Author:

17 Paul Martin ${ }^{1}$

18 Email address: pm45@queensu.ca 


\section{Abstract}

21 Aggressive interactions among closely related species are common, and can play an important

22 role as a selective pressure shaping species traits and assemblages. The nature of this selective

23 pressure depends on whether the outcomes of aggressive contests are asymmetric between

24 species (i.e., one species is consistently dominant), yet few studies have estimated the prevalence

25 of asymmetric versus symmetric outcomes to aggressive contests. Here we use previously

26 published data involving 26,212 interactions between 270 species pairs of birds from 26

27 taxonomic families to address the question: How often are aggressive interactions among closely

28 related bird species asymmetric? We define asymmetry using (i) the proportion of contests won

29 by one species, and (ii) statistical tests for asymmetric outcomes of aggressive contests. We

30 calculate these asymmetries using data summed across different sites for each species pair, and

31 compare results to asymmetries calculated using data separated by location. We find that $80 \%$ of

32 species pairs had aggressive outcomes where one species won $80 \%$ or more of aggressive

33 contests. We also find that the majority of aggressive interactions among closely related species

34 show statistically significant asymmetries, and above a sample size of 52 interactions, all

35 outcomes are asymmetric following binomial tests. Species pairs with dominance data from

36 multiple sites showed the same dominance relationship across locations in $93 \%$ of the species

37 pairs. Overall, our results suggest that the outcome of aggressive interactions among closely

38 related species are usually consistent and asymmetric, and should thus favor ecological and

39 evolutionary strategies specific to the position of a species within a dominance hierarchy. 


\section{INTRODUCTION}

42 Aggressive interactions commonly occur among closely related species (Kruuk, 1976;

Feinsinger, 1976; Willis \& Oniki, 1978; Robinson \& Terborgh, 1995). Such direct interspecific interactions have been shown to play an important role in interference competition for resources, including habitat, food, nest sites, and roost sites (Chappell, 1978; Dhondt \& Eyckerman, 1980; Robertson \& Gaines, 1986; Alatalo \& Moreno, 1987; Wallace, Collier \& Sydeman, 1992;

Dhondt, 2012). Aggressive interactions may also reduce the costs of indirect ecological interactions (Martin, 1988; Martin \& Martin, 2001a; Martin \& Martin, 2001b) that are generally referred to as "apparent competition", such as density-dependent predation or parasitism involving multiple prey or host species (Holt, 1977; Holt \& Kotler, 1987; Holt \& Lawton, 1994).

In these cases, interspecific aggression that leads to the spatial or temporal exclusion of prey or host species (i.e., individuals of the subordinate species) could reduce the overall density of prey or hosts, and thus reduce predation or infection rates of the dominant species (Martin \& Martin,

54 2001b). Other hypotheses proposed to explain aggressive interactions among species include misplaced aggression (Murray, 1976; Murray, 1981; Murray, 1988; Jones et al., 2016), sexual selection for aggressive displays (Nuechterlein \& Storer, 1985), and practice for intraspecific contests (Nuechterlein \& Storer, 1985); however, evidence to date suggests that many aggressive interactions reflect adaptive responses to reduce ecological costs for one or both species (Robinson \& Terborgh, 1995; Martin \& Martin, 2001b; Leisler, 1988; Palomares \& Caro, 1999; Peiman \& Robinson, 2010; Blowes et al., 2013; Losin et al., 2016). such interactions may have broad consequences for species assemblages and trait evolution 
64 2014; Martin \& Ghalambor, 2014). The nature of these consequences, however, depends on

65 whether the outcome of aggressive interactions between species are symmetric, with both species

66 regularly winning aggressive contests, or asymmetric, with one species winning the majority of

67 aggressive contests. For example, if the outcomes of aggressive interactions are asymmetric, then selection may favor traits in the dominant species that enhance fighting abilities (Young, 2003; Owen-Ashley \& Butler, 2004; Donadio \& Buskirk, 2006) or that signal dominance to other species (Dow, 1975; Flack, 1976; König, 1983; Snow \& Snow, 1984). Asymmetric interactions may also favor traits in the subordinate species that reduce the likelihood of heterospecific aggression, such as traits that reduce ecological overlap with dominant species (Feinsinger, 1976; Willis \& Oniki, 1978; Morse, 1974; König, 1983) or that reduce aggression from dominant species (e.g., the loss of signals that induce aggression from the dominant species, or the evolution of signals that mimic the dominant or other dangerous species; Gill, 1971; Feinsinger \& Chaplin, 1975; Feinsinger \& Colwell, 1978; Rainey \& Grether, 2007; Prum \& Samuelson, 2012; Prum, 2014). Conversely, if aggressive interspecific interactions are typically symmetric, then selection may act similarly on the interacting species, potentially favoring individuals in both species that maintain exclusive territories (Orians \& Willson, 1964; although interspecific territoriality can involve species with asymmetric relations as well). Thus, selection should shape the evolution of species' traits differently if aggressive interactions are symmetric versus asymmetric. Despite the importance of understanding the prevalence of asymmetric relationships among interacting species, relatively little is known about how common such patterns are in nature.

In this paper, we ask: how often are aggressive interactions among closely related species asymmetric? Although the outcomes of many aggressive contests among species are asymmetric 
87 (Morse, 1974; Lawton \& Hassell, 1981; Persson, 1985), few studies have compared the

88 frequency of asymmetric versus symmetric relationships between aggressively interacting

89 species. The studies that have examined this question have found asymmetric interactions to be

90 common: 1) a study of 13 species of surgeonfish (Acanthuridae) on a barrier reef at Aldabra,

91 Indian Ocean, found evidence for asymmetric interactions among 26 of the 27 species pairs that

92 interacted aggressively (Robertson \& Gaines, 1980), 2) a study of closely related species of birds

93 in Amazonian Peru found that 9 of the 12 focal species pairs exhibiting interspecific aggression

94 also showed statistically significant asymmetries in their response to playback of heterospecific

95 songs (Robinson \& Terborgh, 1995), 3) a comparative study of interspecific killing among

96 carnivorous mammals found asymmetric killing (i.e., only one species was known to kill the

97 other, rather than both killing each other) in 18 of 19 species pairs that were within the same

98 taxonomic families (excluding domesticated species; Palomares \& Caro, 1999), and 4) our own

99 comparative study of ecological traits of dominant and subordinate species of North American

100 birds found evidence that 64 of 65 congeneric species pairs had asymmetric outcomes to

101 aggressive interactions (Freshwater, Ghalambor \& Martin, 2014).

102 Here, we compile published, quantitative data on the outcomes of aggressive interactions

103 among species within the same taxonomic families, focusing on birds where interaction data are

104 common. We estimate asymmetries in interactions among species using statistical tests for

105 asymmetries and the proportion of aggressive contests won by each species. Although statistical

106 tests provide an accepted method for identifying asymmetries in the outcomes of interactions

107 (Crawley, 2013), these tests may not be the optimal method for estimating their magnitude,

108 prevalence, or biological importance. For example, a lack of statistically significant dominance

109 asymmetries may simply reflect small sample sizes; in other cases, large sample sizes may result 
110 in statistically significant asymmetries of small biological effect (e.g., 55:45 splits in the

111 outcomes of aggressive interactions). Thus, we also estimated the prevalence of asymmetric

112 interactions by calculating the proportion of aggressive contests won by each species, providing

113 a view of their biological importance that has not been highlighted in other studies to date (e.g.,

114 Freshwater, Ghalambor \& Martin 2014). The outcome of aggressive contests, including which

115 species is behaviorally dominant, may also vary across different habitats or geographic locales

116 (Altshuler, 2006; Carstensen et al., 2011), but the frequency of such variation has not previously

117 been explored. To test how common asymmetric aggressive interactions are in birds, we

118 examined the outcome of contests across diverse groups of birds, including vultures feeding at

119 carcasses, hummingbirds feeding at nectar sources, antbirds and woodcreepers feeding on prey

120 fleeing from army ant swarms, and a broad collection of North American congeners. Where

121 possible, we also examined if the outcome of aggressive interactions between the same species

122 pairs changed between different geographic locations. Collectively, we present results from data

123 representing 270 interacting pairs of species from 26 families, and including the outcomes of

12426,212 interactions.

125

126 MATERIALS \& METHODS

\section{Interaction data}

128 We used published data from Freshwater, Ghalambor \& Martin (2014) and Martin \&

129 Ghalambor (2014), supplemented with additional quantitative data, including published data for

130 interactions that had been excluded from Martin \& Ghalambor (2014) because of a lack of

131 genetic or mass data for the interacting species. This study did not require vertebrate ethics

132 approvals because we used published data in a comparative test supplemented with a few 
133 additional natural history observations. For data on North American congeners, we included only

134 the youngest phylogenetically-independent species pair for which we had quantitative data on the

135 outcomes of aggressive interactions (Freshwater, Ghalambor \& Martin 2014). We note that

136 examining only the youngest phylogenetically-independent species pairs was important in our

137 previous work that focused on the evolution of traits associated with dominance status

138 (Freshwater, Ghalambor \& Martin 2014), but was not part of our approach to addressing the

139 focal questions of this study. The complete datasets and sources for all of the data are included as

140 supplementary files Data S1-S3. Overall, we created two different datasets: (1) all of the data

141 combined, including data for species interactions that were gathered from multiple sites and

142 summed together for each species pair (Data S2), and (2) the same data entered for each

143 individual location separately, and where each location had at least 6 observations per species

144 pair (Data S3). We included data separated by location to address the potential effects of lumping

145 data across geographic locations on our results. Separating data by location also allowed us to

146 test for geographic variation in dominance relationships among species using the cases where the

147 same species pairs had interaction data from multiple locations. For all datasets, we included

148 only species pairs (Data S2) or locations (Data S3) that had at least 6 interactions with clear

149 outcomes (i.e., one species clearly won the interaction). We rarely had data on the number of

150 individuals involved across interactions, in part because most studies of aggressive interactions

151 did not involve marked individuals. Thus, for some of the species pairs, the number of

152 interactions includes some degree of pseudoreplication (where the same individual was involved

153 in multiple aggressive interactions), but the extent of pseudoreplication across our dataset is

154 unknown. Following the previous work, we included chases, supplants and displacements,

155 kleptoparasitism, and physical attacks as aggressive interactions (see Freshwater, Ghalambor \& 
156 Martin 2014 for definitions of these terms). We excluded observations that involved the defense

157 of eggs or young and avoided interactions involving more than one individual of each species

158 (following Freshwater, Ghalambor \& Martin 2014; Martin \& Ghalambor, 2014). We included

159 observations related to competition for nest sites, because many birds compete aggressively with

160 other species for nesting sites (e.g., Wallace, Collier \& Sydeman, 1992).

161

162 Statistical tests of asymmetry

163 We tested for asymmetries in the outcomes of aggressive contests between pairs of species using

164 binomial tests in the statistical program $\mathrm{R}$ ( $R$ Core Team, 2014). We ran binomial tests on

165 aggressive interaction data for each species pair in our analysis, and again on our dataset

166 partitioned by location within each species pair. The likelihood of detecting a significant $(P<$

1670.05 ) asymmetry in the outcome of aggressive interactions among species increases with the

168 number of interactions observed (i.e., sample size; Crawley, 2013), so we plotted $P$-values as a

169 function of sample size for all species pairs.

170

\section{Proportion of interactions won}

172 We also tested for asymmetries in the outcomes of aggressive contests between pairs of species

173 by examining the proportion of interactions won by one species. We know of no cut-off for

174 designating interactions as asymmetric, so we plotted the cumulative number of species pairs

175 showing asymmetric outcomes to their interactions, varying the definition of asymmetric from

$176>60 \%$ to $100 \%$ of the interactions won by the dominant. As before, we plotted these relationships

177 for data summarized by species pairs, and again for data partitioned by location within each

178 species pair. 


\section{Variation in dominance among locations}

181 For species pairs with dominance data from multiple locations (each location with greater than 6

182 interactions per species pair), we looked at the frequency with which dominance status switched

183 between species among locations, and tested for differences in the proportion of aggressive

184 contests won by each species between sites using Chi-squared tests in R ( $R$ Core Team, 2014).

185 We estimated the distance between different geographic locations for each species pair by

186 recording the latitude and longitude in decimal degrees for each site (from the original references,

187 or estimated based on the description of the site within the original references), and then

188 calculating the distance between these points in $\mathrm{km}$ using the deg.dist function in the $\mathrm{R}$ package

189 fossil (Vavrek 2012).

190

191 RESULTS

\section{Statistical tests of asymmetry}

193 Overall, 224 of 270 species pairs $(83.0 \%)$ showed statistically significant $(P<0.05)$ asymmetries

194 in the outcomes of aggressive contests. Above a sample size of 52, all aggressive interactions

195 among species were statistically significant $(P<0.05)$ (Fig. 1). Data partitioned by location

196 within species pairs revealed similar results: 235 of 288 comparisons $(81.6 \%)$ showed

197 statistically significant $(P<0.05)$ asymmetries in the outcomes of aggressive contests.

198

199 Proportion of interactions won

200 For data summarized by species pair, $79.6 \%$ of species pairs had dominant species that won

$201 \geq 80 \%$ of the aggressive contests (range across groups: $72.2 \%$ for vultures to $86.2 \%$ for antbirds 
202 and woodcreepers; Fig. 2). In contrast, 97.0\% of species pairs had dominant species that won

$203 \geq 60 \%$ of the aggressive contests (range across groups: $95.6 \%$ for hummingbirds to $100.0 \%$ for

204 vultures), while $48.1 \%$ of species pairs had dominant species that won $100 \%$ of the aggressive

205 contests (range across groups: $27.8 \%$ for vultures to $64.6 \%$ for antbirds and woodcreepers) (Fig.

206 2). Data partitioned by location within species pairs revealed similar results.

207

208 Variation in dominance among locations

209 Across all species pairs, 28 had aggressive interaction data from more than one location (with

210 over 6 interactions observed from each location); 21 species pairs had data for 2 locations, 7

211 species pairs had data for 3 locations. The average distance among geographic locations within

212 species pairs was $1,176 \mathrm{~km}$ (range $13-4,184 \mathrm{~km}$; all distance data are available in

213 supplementary file Data S4).

214 Dominance relationships within species pairs were consistent across sites (i.e., the same

215 species won the majority of the interactions at both or all three locations) in 26 of the 28 species

216 pairs (92.9\%). The 2 species pairs whose dominance relationship flipped between locations

217 included one pair of vultures (Accipitridae: Rüppell's Vulture, Gyps rueppellii_-White-backed

218 Vulture, Gyps africanus, Amboseli National Park, Kenya and Serengeti National Park, Tanzania)

219 and one pair of hummingbirds (Trochilidae: Glittering-bellied Emerald, Chlorostilbon lucidus-

220 Ruby-topaz Hummingbird, Chrysolampis mosquitus, Serra do Pará, Pernambuco, Brazil and

221 Cadeia do Espinhaço, Bahia, Brazil). For 5 of the 28 species pairs (17.9\%; including the 2 for

222 which dominance relationships flipped between sites), the proportions of aggressive contests

223 won by each species were significantly different among locations (i.e., Chi-squared test, $P<$ 
$2240.05)$. For the remaining 23 species pairs $(82.1 \%)$, the proportion of aggressive contests won by

225 each species did not differ significantly across sites.

226 In addition to consistent dominance relationships among locations, species pairs also

227 showed the same dominance relationships in winter and summer ( $N=2$ migrant species pairs;

228 Bucephala islandica-clangula; Anas strepera-americana) and in captive versus wild

229 populations ( $N=3$ species pairs; Ammodramus maritimus - caudacutus; Melospiza melodia-

230 georgiana; Spinus psaltria - lawrencei), suggesting that such asymmetries are repeatable across

231 different contexts.

232

\section{DISCUSSION}

234 Whether the outcome of aggressive interactions is commonly symmetric or asymmetric has 235 important ecological and evolutionary implications. We found the outcomes of most aggressive

236 interactions among species within the same taxonomic bird family were asymmetric. Overall,

$23783 \%$ of the 270 species pairs showed statistically significant asymmetries in the outcome of

238 aggressive contests (i.e., binomial tests, $P<0.05$; Fig. 1), with all species pairs showing

239 statistically significant asymmetries above a sample size of 52 interactions. When we

240 characterized asymmetry using the proportion of interactions won by the dominant species, we

241 found that $80 \%$ of the species pairs contained dominant species that won $80 \%$ or more of

242 aggressive contests (Fig. 2). For 28 species pairs, we had dominance data for 2 or 3 different

243 populations, allowing us to test whether dominance asymmetries among species were consistent

244 across locations. Dominance relationships were the same across locations for $93 \%$ of the species

245 pairs (i.e., the same species won the majority of aggressive contests across the different

246 locations), while the proportion of interactions won by each species was not significantly 
247 different across locations for $82 \%$ of the species pairs. These results suggest that dominance

248 relationships between species are usually consistent across different sites. Below, we discuss the

249 ecological and evolutionary consequences of asymmetric interactions, the factors that underlie

250 dominance, the possible reasons to explain the few cases where dominance differed across

251 different locations, and the implications for how dominant and subordinate species respond to

252 human impacts.

253

254 Asymmetric interactions and their consequences for ecology

255 Asymmetric outcomes to most aggressive interactions suggest that dominant species can use

256 preferred resources and reduce the access of subordinate species to those resources (Morse,

257 1974). Such patterns are not unique to birds, as experiments have demonstrated asymmetric

258 partitioning of resources in invertebrates (Bovbjerg, 1970; Bertness, 1981a; Bertness, 1981b) and

259 across a diverse array of vertebrates (Chappell, 1978; Robertson \& Gaines, 1986; Alatalo \&

260 Moreno, 1987; Martin \& Martin, 2001a; Hixon, 1980; Larson, 1980; Alatalo et al., 1985;

261 Alatalo et al., 1987; Ziv et al., 1993; Pasch, Bolker \& Phelps, 2013). In these cases, subordinates

262 are excluded from preferred resources, but are still able to use resources that cannot sustain

263 dominant species, and thus are not preferentially defended (Morse, 1974; Martin, 2014). The

264 result is a repeated pattern: dominant species direct aggression towards subordinate species

265 (interference competition), restricting resource use for the subordinate species.

266 The strong asymmetries in the outcomes of aggressive contests also suggest that trade-

267 offs involving aggressive ability and behavioral dominance could play an important role in the

268 partitioning of resources and coexistence of species, particularly among closely related species.

269 For example, a smaller body size requires fewer resources to grow, survive, and reproduce, but 
270 comes at a cost in the form of losing aggressive contests to larger species (Peters, 1983; see also

271 below). Given that resources vary in time and space, large- and small-sized species could coexist

272 by partitioning habitats according to the abundance of resources, with aggressive interactions

273 among species playing a central role in habitat partitioning (Morse, 1974; Ford, 1979; Diamond

274 et al., 1989; Martin, 2014). We might expect other trade-offs involving aggressive abilities to

275 lead to similar patterns of resource partitioning and coexistence among species of birds and other

276 taxa (e.g., Feinsinger, 1976; Willis \& Oniki, 1978; Feinsinger \& Colwell, 1978).

277

278 Asymmetric interactions and their consequences for evolution

279 Asymmetric aggressive interactions should represent an important selection pressure between 280 interacting species (Grether et al., 2009; Pfennig \& Pfennig, 2012; Grether et al., 2013). Our

281 results suggest that we should expect such selection to favor the evolution of distinct traits and 282 strategies that depend on the position of species within a dominance hierarchy (Morse, 1974;

283 Gauthreaux, 1978; Grether et al., 2013; Freshwater, Ghalambor \& Martin, 2014). For example,

284 selection may favor investment in aggression or territorial behavior in dominant species, even

285 when such traits incur some fitness costs or trade-off with other traits. Selection may also favor

286 traits, such as color patterns or displays, that signal dominance status to subordinate species in

287 order to reduce the frequency and cost of aggressive encounters among species (see Flack, 1976;

288 König, 1983; Snow \& Snow, 1984 for possible examples of these traits).

289 In contrast, selection might favor traits in subordinate species that reduce the costs of

290 aggressive interactions with dominants. For example, the evolution of color patterns or displays

291 in subordinate species may reduce aggression from dominant species, and thus be favored by

292 natural selection (Gill, 1971; Scetre, Král \& Bičík, 1993). The evolution of mimicry of dominant 
293 species by subordinates may also be an underappreciated outcome of asymmetric interactions

294 among species. In birds, recent evidence suggests that the mimicry of dominant species by

295 subordinates could be widespread, involving both song and color patterns (Cody, 1973; Rainey \&

296 Grether, 2007; Prum \& Samuelson, 2012; Prum, 2014). Similarly, selection should favor traits

297 that facilitate alternative ecological strategies that reduce the costs of aggressive contests with

298 dominant species. Such alternative strategies could include altering the timing of breeding or

299 geographic distribution to reduce temporal and spatial overlap with dominant species

300 (Freshwater, Ghalambor \& Martin, 2014), or evolving adaptations that allow subordinate

301 species to use novel resources (e.g., physiological tolerance to conditions outside those

302 experienced in a clade). With reduced access to important resources for survival, such as food

303 and safe roosting sites, subordinate species might also be more likely to evolve distinct life

304 history strategies that invest more in annual reproductive effort at the expense of annual survival

305 (Roff, 1992; Stearns, 1992). Indeed, such patterns characterize dominant and subordinate species

306 within a genus: subordinate species have lower annual survival rates and lay larger eggs for a

307 given body mass (Freshwater, Ghalambor \& Martin, 2014).

308

309 What causes variation in the asymmetric outcomes of aggressive encounters among

310 species?

311 Many factors have been identified as influencing the proportion of encounters won by dominant

312 species, including age and sex (Stiles, 1973), as well as proximate factors that include condition,

313 hunger level, density, and time of arrival or colonization (Stiles, 1973; Lyon, 1976; Anderson \&

314 Horwitz, 1979; Cole, 1983; Wallace \& Temple, 1987; Robinson, 1989; Tanner \& Adler, 2009).

315 Perhaps the most important predictor of the outcome of aggressive contests, however, appears to 
316 be differences in body size among the interacting species (Morse, 1974; Peters, 1983; Robinson

317 \& Terborgh, 1995; Donadio \& Buskirk, 2006; Martin \& Ghalambor, 2014). Indeed, in the

318 results we report here, the larger species was dominant in $87 \%$ of the contests where the

319 outcomes of aggressive contests were asymmetric (defined as $\geq 80 \%$ of contests won by the

320 dominant species), with the dominant species averaging $57 \%$ heavier than the subordinate (for a

321 list of reasons why larger size confers an advantage in aggressive contests, see Martin \&

322 Ghalambor, 2014). This contrasts with cases where one species won between 50-69\% of the

323 contests (i.e., the outcome was more symmetric), where the larger species prevailed in only $67 \%$

324 of the species pairs and averaged only $25 \%$ heaver (data in supplemental file Data S2).

325 The importance of body size for determining the outcomes of aggressive contests,

326 however, can vary. For example, larger species win a greater proportion of aggressive

327 interactions as the difference in body size between interacting species increases, but this

328 relationship weakens with greater evolutionary distance among the interacting species (Martin \&

329 Ghalambor, 2014). We hypothesize that this pattern occurs because closely related species share

330 more traits with each other (Violle et al., 2011), and thus differences in size alone can determine

331 the outcome of aggressive interactions (Martin \& Ghalambor, 2014). As species become more

332 distantly related, however, they are more likely to accumulate unique traits that influence

333 behavioral dominance independent of body size. Indeed, Martin \& Ghalambor (2014) found that

334 as species became more distantly related, the outcome of aggressive interactions became more

335 asymmetric independent of differences in body size. Few studies, however, have attempted to

336 identify the exact suite of traits that explain dominance independent of body size (Donadio \&

337 Buskirk, 2006; Martin \& Ghalambor, 2014). 
339 The rare flip: why does dominance shift for some species pairs across sites?

340 Although the outcomes of aggressive interactions were usually asymmetric and consistent across

341 different locations, the dominant species differed across sites for two pairs of interacting species.

342 We could not determine the cause of the variation in dominance among sites in either of these

343 cases, although the two different vulture studies categorized the outcomes of aggressive

344 interactions in different ways, which could have contributed to the different patterns (Kruuk,

345 1967; Anderson \& Horwitz, 1979). Studies of other examples of dominance flipping, however,

346 help to shed light on when and why such cases arise.

347 The most detailed study of shifting dominance across sites examined the relative fighting

348 performance of hummingbirds at different elevations. Rufus Hummingbirds (Selasphorus rufus)

349 dominate Broad-tailed Hummingbirds (S. platycercus) at low elevations in Colorado, USA, but

350 are subordinate at higher elevations (Altshuler, 2006). The dominance reversal across elevations

351 appears to result from differences in wing loading between the species and how changes in air

352 pressure alter flight performance (Altshuler, 2006). Specifically, at high elevations, the long-

353 winged Broad-tailed Hummingbird appears better able to achieve burst power performance, and

354 thus dominates Rufus Hummingbirds; at low elevations, burst power is unconstrained, and the

355 greater maneuverability and sustained aerodynamic performance of the shorter-winged Rufus

356 Hummingbird appears to provide a competitive advantage over Broad-tailed Hummingbirds in

357 aggressive contests (Altshuler, 2006).

358 Similar variation in fighting abilities may also characterize species interactions in the air

359 versus on the ground (or water), especially because a heavier weight improves fighting abilities

360 on the ground, but can compromise aerial maneuverability that can influence the outcome of

361 aggressive contests in the air (see Peters, 1983; Bonner, 2006). Such trade-offs in performance 
362 may explain different outcomes to aggressive contests for some species pairs (that were not part

363 of our dataset in this paper); for example, Whistling Kites, Haliastur sphenurus, and European

364 Herring Gulls, Larus argentatus, are dominant to Black Kites, Milvus migrans, and Audouin's

365 Gulls, Ichthyaetus audouinii, respectively, on the ground, but are subordinate to them in the air

366 (Marchant \& Higgins, 1993: page 74; Cramp, 1983: page 784). Such trade-offs may be more

367 widespread than is presently recognized, particularly in birds that commonly interact in both

368 aerial and terrestrial contexts (e.g., Laridae, Accipitridae, Corvidae).

369

The relative densities of subordinate species can also influence the outcomes of

370

aggressive contests, and cause variation in dominance across sites. In our study, interactions

371 between Blue-throated (Lampornis clemenciae) and Magnificent (Eugenes fulgens)

372 hummingbirds differed significantly between locations, with Blue-throateds dominant at two

373 sites, but no significant difference in the number of contests won between the species at a third

374 site. High densities of the subordinate Magnificent Hummingbird at the third site was thought to

375 have created this shift; individuals of the dominant Blue-throated Hummingbird were more likely

376 to abort and retreat from an aggressive interaction when they encountered high densities of

377 subordinates, presumably because winning one interaction would be unlikely to give them

378 sufficient access to the resource (Lyon, 1976). Thus, the density of subordinate species can

379 influence the outcome of individual interactions, even with a lack of coordinated fighting among

380 individuals (Lyon, 1976; Martin \& Ghalambor, 2014). This influence of subordinate density is

381 thought to explain variation in the outcomes of aggressive interactions across sites and contexts

382 in vultures, hummingbirds, blackbirds, and perhaps other groups, where subordinate species

383 show substantial variation in their densities (Orians, 1961; Orians \& Collier, 1963; Lyon, 1976;

384 König, 1983; Wallace \& Temple, 1987; Houston, 1988; Kirk, 1988; Buckley, 1996). 

composition or activities of populations over time or space, particularly with respect to age, sex, and territorial behavior. For example, adult male Anna's Hummingbirds (Calypte anna) dominated adult male Costa's Hummingbirds (C. costae) in 23 of 25 interactions $(92 \%)$; in contrast, immature Anna's Hummingbirds won only 2 of 20 interactions (10\%) with adult male Costa's Hummingbirds (Stiles, 1973). The relative distributions of males and females, and adults and immatures, vary because sexes and age classes show different seasonal movements and distributions in many species (King, Farner \& Mewaldt, 1965; Myers, 1981). In addition, territorial behavior and associated aggression often varies over time and space (Nelson, Badura times or in different sites. All of these factors, from the density of air to the territorial behavior of individuals can cause dominance relationships to flip between species at different sites. The rarity of this dominance flipping in our dataset, however, suggests that the most important determinants of dominance across species remain consistent regardless of geography, and despite the many other factors that can influence the outcomes of aggressive contests.

400

\section{Asymmetric interactions and their consequences for human impacts}

402 Given repeated patterns of dominance and asymmetric interactions among species, we might expect species to differ in their responses to anthropogenic challenges, such as climate change and habitat alteration, depending on their position within a dominance hierarchy. Some subordinate species appear to be better able to persist in degraded habitats (Daily \& Ehrlich, 1994), and may have greater ecological breadth and tolerance compared to dominant species

407 (Morse, 1974; Minot \& Perrins, 1986; Blowes, Pratchett \& Connolly, 2013; but see Freshwater, 
408 Ghalambor \& Martin, 2014). Aggression and behavioral dominance, however, are often

409 associated with boldness that can help species cope in the face of human disturbance (Evans,

410 Boudreau \& Hyman, 2010; Lowry, Lill \& Wong, 2013). Thus, traits that covary with dominance

411 status could facilitate or hinder species in the face of human alteration of habitats. Regardless,

412 the importance of asymmetric interactions in determining patterns of resource use among species

413 suggests that these interactions may mediate species' responses to perturbations like habitat

414 alteration or climate change. Few models consider these kinds of species interactions in their

415 forecasts of the impacts of habitat perturbations or climate change on species abundance and

416 distributions (Tylianakis et al., 2008; Gilman et al., 2010; Buckley, 2013). Yet, any impacts on

417 dominant species are likely to have cascading effects on the subordinate species with which they

418 interact (Duckworth \& Badyaev, 2007; Gilman et al., 2010; Jankowski, Robinson \& Levey, 2010;

419 Buckley, 2013; Martin \& Dobbs, 2014; Freeman \& Montgomery, 2015; Freeman, Class

420 Freeman \& Hochachka, 2016). Such asymmetric interactions could have important

421 consequences for populations, particularly in environments where the options for dispersal and

422 range shifting are limited (e.g., tropical islands and mountains; Jankowski, Robinson \& Levey,

423 2010; Freeman, 2016).

424

425 ACKNOWLEDGEMENTS

426 We thank Fran Bonier for helpful insight and discussion, and Ben Freeman and Greg Grether for 427 comments and suggestions that significantly improved the manuscript.

428

429 Data Availability

430 Our data are included with this submission as supplementary files Data S1-S4. 
432

433

434

435

436

437

438

439

440

441

442

443

444

445

446

447

448

449

450

451

452

\section{REFERENCES}

Alatalo RV, Eriksson D, Gustafsson L, Larsson K. 1987. Exploitation competition influences the use of foraging sites by tits: experimental evidence. Ecology 68:284-290.

Alatalo RV, Gustafsson L, Linden M, Lundberg A. 1985. Interspecific competition and niche shifts in tits and the goldcrest: an experiment. Journal of Animal Ecology 54:977-984.

Alatalo RV, Moreno J. 1987. Body size, interspecific interactions, and use of foraging sites in tits (Paridae). Ecology 68:1773-1777.

Altshuler DL. 2006. Flight performance and competitive displacement of hummingbirds across elevational gradients. American Naturalist 167:216-229.

Anderson DJ, Horwitz RJ. 1979. Competitive interactions among vultures and their avian competitors. Ibis 121:505-509.

Bertness MD. 1981a. Predation, physical stress, and the organization of a tropical rocky intertidal hermit crab community. Ecology 62:411-425.

Bertness MD. 1981b. Competitive dynamics of a tropical hermit crab assemblage. Ecology 62:751-761.

Blowes SA, Pratchett MS, Connolly SR. 2013. Heterospecific aggression and dominance in a guild of coral feeding fishes: the roles of dietary ecology and phylogeny. American Naturalist 182:157-168.

Bonner JT. 2006. Why size matters. Princeton: Princeton University Press.

Bovbjerg H. 1970. Ecological isolation and competitive exclusion in two crayfish (Orconectes virillis and Orconectes immunis). Ecology 51:225-236. 
453 Buckley LB. 2013. Get real: putting models of climate change and species interactions in practice. Annals of the New York Academy of Sciences 1297:126-138.

455

456

457

458

459

460

461

462

463

464

465

466

467

468

469

470

471

472

473

474

475

Buckley NJ. 1996. Food finding and the influence of information, local enhancement, and communal roosting on foraging success of North American vultures. Auk 113:473-488.

Carstensen DW, Sweeny R, Ehlers B, Olesen JM. 2011. Coexistence and habitat preference of two honeyeaters and a sunbird on Lombok, Indonesia. Biotropica 43:351-356.

Chappell MA. 1978. Behavioral factors in the altitudinal zonation of chipmunks (Eutamias). Ecology 59:565-579.

Cody ML. 1973. Character convergence. Annual Review of Ecology and Systematics 4:189-211.

Cole BJ. 1983. Assembly of mangrove ant communities: patterns of geographical distribution. Journal of Animal Ecology 52:339-347.

Cramp S. (ed) 1983. The birds of the Western Palearctic. Vol. III. Waders to gulls. Oxford: Oxford University Press.

Crawley MJ. 2013. The R book, second edition. Chichester: John Wiley \& Sons.

Daily GC, Ehrlich PR. 1994. Influence of social status on individual foraging and community structure in a bird guild. Oecologia 100:153-165.

Dhondt AA. 2012. Interspecific competition in birds. Oxford: Oxford University Press.

Dhondt AA, Eyckerman R. 1980. Competition between the great tit and the blue tit outside the breeding season in field experiments. Ecology 61:1291-1296.

Diamond J, Pimm SL, Gilpin ME, LeCroy M. 1989. Rapid evolution of character displacement in Myzomelid honeyeaters. American Naturalist 134:675-708.

Donadio E, Buskirk SW. 2006. Diet, morphology, and interspecific killing in Carnivora. American Naturalist 67:524-536. 
476 Dow DD. 1975. Displays of the honeyeater Manorina melanocephala. Zeitschrift für

$477 \quad$ Tierpsychologie 38:70-96.

478 Duckworth RA, Badyaev AV. 2007. Coupling of dispersal and aggression facilitates the rapid

479

480

481

482

483

484

485

486

487

488

489

490

491

492

493

494

495

496

497 range expansion of a passerine bird. Proceedings of the National Academy of Sciences of the USA 104:15017-15022.

Evans J, Boudreau K, Hyman J. 2010. Behavioural syndromes in urban and rural populations of song sparrows. Ethology 116:588-595.

Feinsinger P. 1976. Organization of a tropical guild of nectarivorous birds. Ecological Monographs 46:257-291.

Feinsinger P, Chaplin SB. 1975. On the relationship between wing disc loading and foraging strategy in hummingbirds. American Naturalist 109:217-224.

Feinsinger P, Colwell RK. 1978. Community organization among neotropical nectar-feeding birds. American Zoologist 18:779-795.

Flack JAD. 1976. The use of frontal spot and crown feathers in inter- and intraspecific display by the South Island Robin Petroica australis australis. Notornis 23:90-105.

Ford HA. 1979. Interspecific competition in Australian honeyeaters - depletion of common resources. Australian Journal of Ecology 4:145-164.

Freeman BG. 2016. Strong asymmetric interspecific aggression between two sympatric New Guinean robins. Ibis 158:75-81.

Freeman BG, Class Freeman AM, Hochachka WM. 2016. Asymmetric interspecific aggression in New Guinean songbirds that replace one another along an elevational gradient. Ibis 158:726-737. 
498 Freeman BG, Montgomery, G. 2015. Interspecific aggression by the Swainson's Thrush 499 (Catharus ustulatus) may limit the distribution of the threatened Bicknell's Thrush 500 (Catharus bicknelli) in the Adirondack Mountains. Condor 118:169-178.

501 Freshwater C, Ghalambor CK, Martin PR. 2014. Repeated patterns of trait divergence 502 between closely related dominant and subordinate bird species. Ecology 95:2334-2345.

503 Gauthreaux SA Jr. 1978. The ecological significance of behavioral dominance. In: Bateson 504 PPG, Klopfer PH, eds. Perspectives in ethology. New York: Plenum Press, 17-54.

505

506

507

508

509

510

511

512

513

514

515

516

517

518

519

520

Gill FB. 1971. Ecology and evolution of the sympatric Mascarene white-eyes, Zosterops borbonica and Zosterops olivacea. Auk 88:35-60.

Gilman SE, Urban MC, Tewksbury J, Gilchrist GW, Holt RD. 2010. A framework for community interactions under climate change. Trends in Ecology and Evolution 25:325331.

Grether GF, Anderson CN, Drury JP, Kirschel ANG, Losin N, Okamoto K, Peiman KS. 2013. The evolutionary consequences of interspecific aggression. Annals of the New York Academy of Sciences 1289:48-68.

Grether GF, Losin N, Anderson CN, Okamoto K. 2009. The role of interspecific interference competition in character displacement and the evolution of competitor recognition. Biological Reviews 84:617-635.

Hixon MA. 1980. Competitive interactions between California reef fishes of the genus Embiotica. Ecology 61:918-931.

Holt RD. 1977. Predation, apparent competition, and the structure of prey communities. Theoretical Population Biology 12:197-229.

Holt RD, Kotler BP. 1987. Short-term apparent competition. American Naturalist 130:412-430. 
521 Holt RD, Lawton JH. 1994. The ecological consequences of shared natural enemies. Annual $522 \quad$ Review of Ecology and Systematics 25:495-520.

523 Houston DC. 1988. Competition for food in Neotropical vultures in forest. Ibis 130:402-417.

524 Jankowski JE, Robinson SK, Levey DJ. 2010. Squeezed at the top: interspecific aggression 525 may constrain elevational ranges in tropical birds. Ecology 91:1877-1884.

526 Jones JA, Tisdale AC, Tucker JL, Bakermans MH, Larkin JL, Smalling CG, Siefferman L. 527 2016. A case of mistaken identity: understanding the stimulus of agonism between two 528 wood warblers. Animal Behaviour 114:81-91.

529

King JR, Farner DS, Mewaldt LR. 1965. Seasonal sex and age ratios in populations of the 530 White-crowned Sparrows of the race gambelii. Condor 67:489-504.

531

532

533

534

535

536

537

538

539

540

541

542

Kirk DA. 1988. Ecological separation of small Cathartid vultures in South America. PhD thesis. Glasgow: University of Glasgow.

König C. 1983. Interspecific and intraspecific competition for food among Old World vultures. In: Wilbur SR, Jackson JA, eds. Vulture biology and management. Berkeley: University of California Press, 153-171.

Kruuk H. 1967. Competition for food between vultures in east Africa. Ardea 55:171-193.

Larson RJ. 1980. Competition, habitat selection, and the bathymetric segregation of two rockfish (Sebastes). Ecological Monographs 50:221-239.

Lawton JH, Hassell MP. 1981. Asymmetrical competition in insects. Nature 289:793-795.

Leisler B. 1988. Interspecific interactions among European marsh-nesting passerines. In: Ouellet H, ed. Acta XIX Congressus Internationalis Ornithologici, Vol. 2. Ottawa: Ottawa University Press, 2635-2644. 
543 Losin N, Drury JP, Peiman KS, Storch C, Grether GF. 2016. The ecological and evolutionary

$544 \quad$ stability of interspecific territoriality. Ecology Letters 19:260-267.

545 Lowry H, Lill A, Wong B. 2013. Behavioural responses of wildlife to urban environments.

$546 \quad$ Biological Reviews 88:537-549.

547 Lyon DL. 1976. A montane hummingbird territorial system in Oaxaca, Mexico. Wilson Bulletin

$548 \quad \mathbf{8 8 : 2 8 0 - 2 9 9 .}$

549 Marchant S, Higgins PJ. (eds) 1993. Handbook of Australian, New Zealand and Antarctic

550 Birds. Volume 2: Raptors to lapwings. Melbourne: Oxford University Press.

551 Martin PR. 2014. Trade-offs and biological diversity: integrative answers to ecological

552 questions. In: Martin LB, Ghalambor CK, Woods HA, eds. Integrative organismal biology.

553 New York: John Wiley \& Sons, 291-308.

554 Martin PR, Dobbs RC. 2014. Asymmetric response to heterospecific songs in two sympatric

555 wrens (Troglodytidae) in Argentina: House Wren (Troglodytes aedon) and Mountain Wren

556 (T. solstitialis). Ornitología Neotropical 25:407-419.

557 Martin PR, Ghalambor CK. 2014. When David beats Goliath: The advantage of large size in 558 interspecific aggressive contests declines over evolutionary time. PLoS ONE 9: e108741.

559 Martin PR, Martin TE. 2001a. Ecological and fitness consequences of species coexistence: a

560 removal experiment with wood warblers. Ecology 82:189-206.

561 Martin PR, Martin TE. 2001b. Behavioral interactions between coexisting species: song 562 playback experiments with wood warblers. Ecology 82:207-218.

563 Martin TE. 1988. On the advantage of being different: nest predation and the coexistence of

564 bird species. Proceedings of the National Academy of Sciences of the USA 85:2196-2199. 
565 Minot EO, Perrins CM. 1986. Interspecific interference competition — nest sites for blue and $566 \quad$ great tits. Journal of Animal Ecology 55:331-350.

567 Morse DH. 1974. Niche breadth and social dominance. American Naturalist 108:818-830.

568 Murray BG. 1976. Critique of interspecific territoriality and character convergence. Condor $569 \quad 78: 518-525$.

570 Murray BG. 1981. The origins of adaptive interspecific territorialism. Biological Reviews of the 571 Cambridge Philosophical Society 56:1-22.

572 Murray BG. 1988. Interspecific territoriality in Acrocephalus: a critical review. Ornis $573 \quad$ Scandinavica 19:309-313.

574 Myers JP. 1981. A test of three hypotheses for latitudinal segregation of the sexes in wintering 575 birds. Canadian Journal of Zoology 59:1527-1534.

576 Nelson RJ, Badura LL, Goldman BD. 1990. Mechanisms of seasonal cycles of behavior. 577 Annual Review of Psychology 41:81-108.

578 Nuechterlein GL, Storer RW. 1985. Aggressive behavior and interspecific killing by Flying 579 Steamer-Ducks in Argentina. Condor 87:87-91.

580 Orians GH. 1961. The ecology of blackbird (Agelaius) social systems. Ecological Monographs 581 31:285-312.

582 Orians GH, Collier G. 1963. Competition and blackbird social systems. Evolution 17:449-459. 583 Orians GH, Willson MF. 1964. Interspecific territories of birds. Ecology 45:736-745.

584 Owen-Ashley NT, Butler LK. 2004. Androgens, interspecific competition and species 585 replacement in hybridizing warblers? Proceedings of the Royal Society, Series B 586 271:S498-S500. 
587 Palomares F, Caro TM. 1999. Interspecific killing among mammalian carnivores. American $588 \quad$ Naturalist 153:492-508.

589 Pasch B, Bolker BM, Phelps SM. 2013. Interspecific dominance via vocal interactions mediates 590 altitudinal zonation in Neotropical singing mice. American Naturalist 182:E161-E173.

591 Peiman KS, Robinson BW. 2010. Ecology and evolution of resource-related heterospecific

592 aggression. Quarterly Review of Biology 85:133-158.

593 Persson L. 1985. Asymmetrical competition: are larger animals competitively superior? 594 American Naturalist 126:261-266.

595 Peters RH. 1983. The ecological implications of body size. Cambridge: Cambridge University 596 Press.

597 Pfennig DW, Pfennig, KS. 2012. Evolution's wedge: competition and the origins of diversity. 598 Berkeley: University of California Press.

599 Prum RO. 2014. Interspecific social dominance mimicry in birds. Zoological Journal of the 600 Linnean Society 172:910-941.

601 Prum RO, Samuelson L. 2012. The Hairy-Downy Game: a model of interspecific social 602 dominance mimicry. Journal of Theoretical Biology 313:42-60.

R Core Team. 2014. $R$ : A language and environment for statistical computing. Vienna: $\mathrm{R}$ 605 Foundation for Statistical Computing. http://www.R-project.org/.

Rainey MM, Grether GF. 2007. Competitive mimicry: synthesis of a neglected class of mimetic relationships. Ecology 88:2440-2448.

Robertson DR, Gaines SD. 1986. Interference competition structures habitat use in a local 608 assemblage of coral reef surgeonfishes. Ecology 67:1372-1383. 
609 Robinson D. 1989. Interspecific aggression and territorial behavior between Scarlet Robin

$610 \quad$ Petroica multicolor and Flame Robin P. phoenicea. Emu 89:93-101.

611 Robinson SK, Terborgh J. 1995. Interspecific aggression and habitat selection by Amazonian birds. Journal of Animal Ecology 64:1-11.

613 Roff DA. 1992. Evolution of life histories: theory and analysis. New York: Springer.

614 Sætre G-P, Král M, Bičík V. 1993. Experimental evidence for interspecific female mimicry in $615 \quad$ sympatric Ficedula flycatchers. Evolution 47:939-945.

616 Snow BK, Snow DW. 1984. Long-term defence of fruit by Mistle Thrushes Turdus viscivorus. Ibis 126:39-49.

618 Stearns SC. 1992. The evolution of life histories. Oxford: Oxford University Press.

619 Stiles FG. 1973. Food supply and the annual cycle of the Anna Hummingbird. University of California Publications in Zoology 97:1-109.

Tanner CJ, Adler FR. 2009. To fight or not to fight: context-dependent interspecific aggression in competing ants. Animal Behaviour 77:297-305.

Tylianakis JM, Didham RK, Bascompte J, Wardle DA. 2008. Global change and species interactions in terrestrial ecosystems. Ecology Letters 11:1351-1363.

Vavrek MJ. 2012. fossil: Palaeoecological and palaeogeographical analysis tools. R package version 0.3.7.

Violle C, Nemergut DR, Pu Z, Jiang L. 2011. Phylogenetic limiting similarity and competitive exclusion. Ecology Letters 14:782-787.

Wallace GE, Collier B, Sydeman WJ. 1992. Interspecific nest-site competition among cavitynesting alcids on southeast Farallon Island, California. Colonial Waterbirds 15:241-244. 
631 Wallace MP, Temple SA. 1987. Competitive interactions within and between species in a guild 632 of avian scavengers. Auk 104:290-295.

633 Willis EO, Oniki Y. 1978. Birds and army ants. Annual Review of Ecology and Systematics $634 \quad 9: 243-263$.

635 Young KA. 2003. Evolution of fighting behavior under asymmetric competition: an 636 experimental test with juvenile salmonids. Behavioral Ecology 14:127-134.

637 Ziv Y, Abramsky Z, Kotler BP, Subach A. 1993. Interference competition and temporal and 638 habitat partitioning in two gerbil species. Oikos 66:237-46.

639 
641 Figure captions

642 Figure 1: Relationship between the number of aggressive interactions observed between 643 each species pair and (A) binomial test $\boldsymbol{P}$-values testing for asymmetries in the outcomes of 644 aggressive interactions, and (B) the proportion of aggressive contests won by the dominant 645 species.

646 In panel (A), the dashed line illustrates the common $P$-value cutoff for statistical significance at

647 0.05. All species pairs with greater than 52 interactions showed statistically significant

648 asymmetries; overall, $83 \%$ of species pairs showed statistically significant asymmetries. In panel

649 (B), box plots show the median as a center line, the interquartile range as a box, values within

$6501.5 *$ interquartile range as whiskers, and all data that lie outside the whiskers as circles. Overall,

65184 species pairs had sample sizes between 6-10 interactions, 151 species pairs had 11-100

652 interactions, and 35 species pairs had $>100$ interactions. 
653
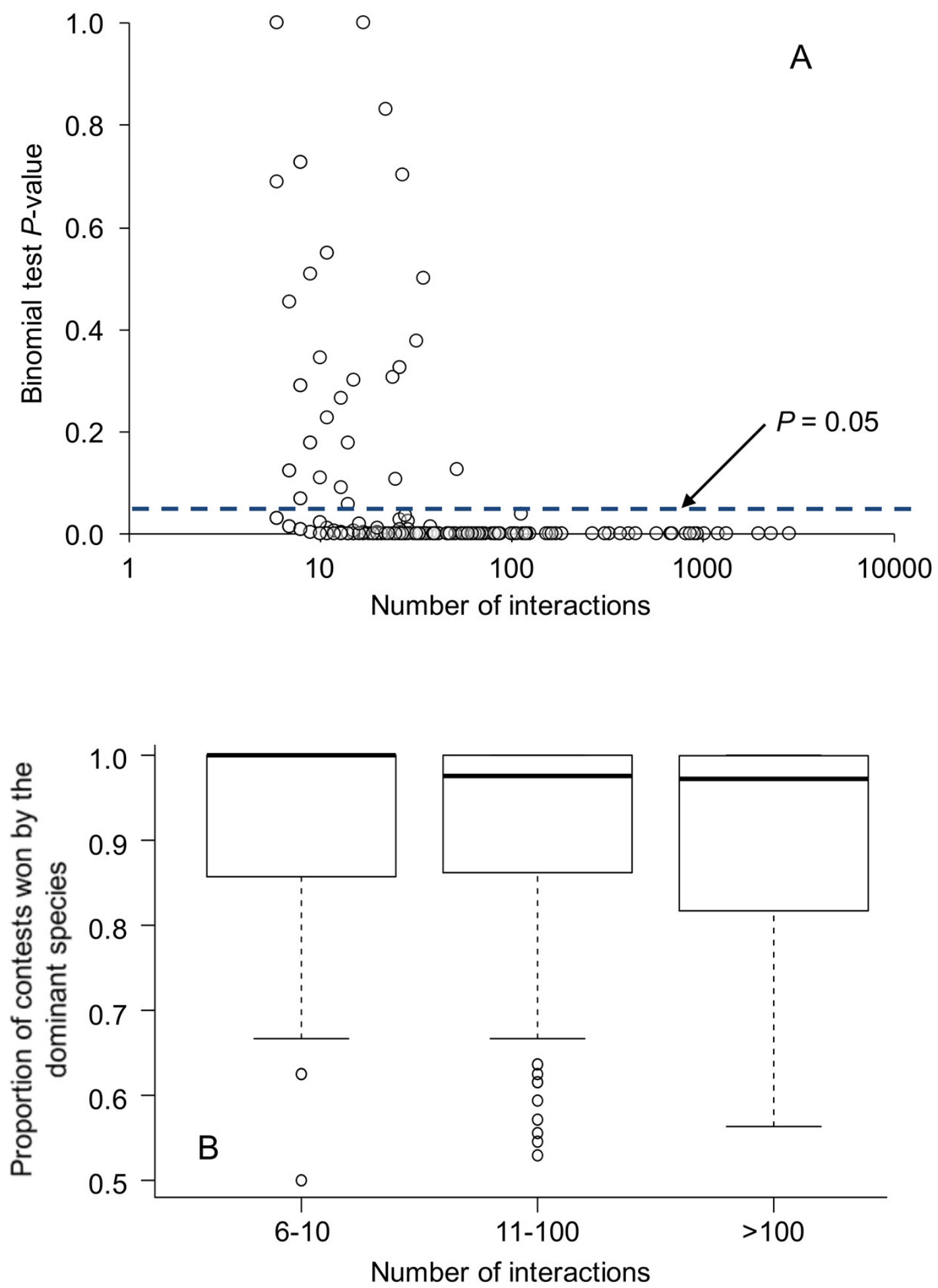
654 Figure 2: The proportion of species pairs showing asymmetric outcomes to their aggressive 655 interactions.

656 Asymmetry was measured by the proportion of interactions won by the dominant species, and

657 was defined on a scale from $>60 \%$ of the interactions won by the dominant species to $100 \%$ of 658 the interactions won by the dominant species (x-axis). The thick black line represents the entire 659 dataset; the blue lines represent different groups within the dataset. Plots are line plots

660 connecting points at $0.01 \mathrm{x}$-value increments. The sample sizes for the different groups are:

661 vultures ( $N=18$ comparisons, 5,820 interactions), hummingbirds ( $N=135$ comparisons, 6,685

662 interactions), woodcreepers and antbirds ( $N=65$ comparisons, 9,263 interactions), North

663 American congeners $(N=52$ comparisons, 4,444 interactions).

664 


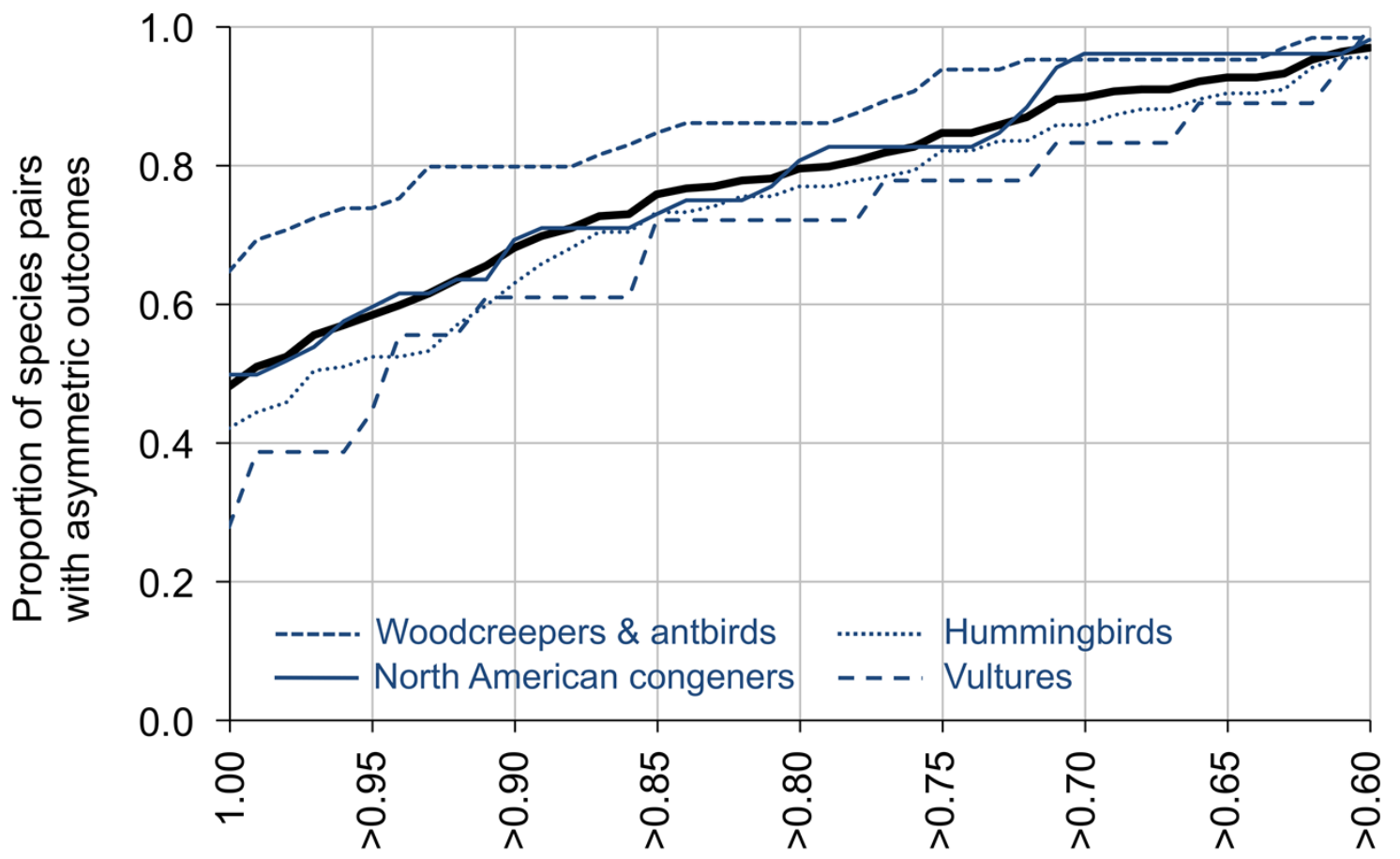

Cutoff for defining asymmetric outcome (Proportion of interactions won by the dominant species) 